changes, but that once diagnosed, conservative management leads to satisfactory control of the symptoms. Key words: Esophagus - Pseudodiverticula Stricture - Hiatal hernia - Candida

Correspondence to: A. H. M. Nassar

\section{The use of ultrasound to demonstrate small bowel polyps in a patient with Peutz-Jeghers syndrome}

A. Y. Izzidien, ${ }^{1}$ R. A. Davies, ${ }^{2}$ A. G. Masoud, ${ }^{1}$ S. Kibru, ${ }^{3}$ A. Abuhamed, ${ }^{1}$ J. S. Lodhi, ${ }^{1}$ G. Abid, ${ }^{1}$ A. Jouanroyee ${ }^{1}$

'Department of Surgery, Prince Charles Hospital, Merthyr Tydfil

CF47 9DT, Wales, United Kingdom

${ }^{2}$ Department of Radiology, Prince Charles Hospital, Merthyr Tydfil CF47 9DT, Wales, United Kingdom

${ }^{3}$ Department of Pathology, Prince Charles Hospital, Merthyr Tydfil

CF47 9DT, Wales, United Kingdom

Received: 13 August 2001/Accepted in final form: 30 October 2001/

Online publication: 8 February 2002

DOI: $10.1007 / \mathrm{s} 00464-001-4230-\mathrm{x}$

\section{Abstract}

A 21-year-old woman presented to the accident and emergency department with a 2-day history of lower abdominal pain. Her lips had the stigma of melanosis. Previously, she had received a diagnosis of Peutz-Jeghers syndrome, although no polyps had been detected in small and large bowel barium studies performed approximately 8 years before. Clinically, the patient had mild deep lower abdominal tenderness, and a mass was palpable in the suprapubic region. Urgent ultrasound showed ileoileal intussusception and small polyps in the lumen of the small bowel. At laparotomy, ileoileal intussusception was confirmed. It was not possible to reduce it because of nonviable small bowel, so $20 \mathrm{~cm}$ of the ileum, including the intussusception, was excised. After this, intraoperative enteroscopy was performed, showing further polyps in the small bowel distal and proximal to the intussusception, which were excised locally. Only a few reports in the literature describe ultrasound used to diagnose to condition. Intraoperative enteroscopy has been recommended as the treatment of choice because it allows identification of polyps that previously would have been missed.

Key words: Peutz-Jeghers syndrome - Ultrasound diagnosis - Intraoperative enteroscopy

Correspondence to: A. Y. Izzidien

\section{Laparoscopic treatment of complications from endoscopic retrograde cholangiopancreatography}

\author{
A. Modrzejewski, T. Hamera, M. Halczak, M. Sledz \\ Pomeranian Academy of Medicine, Department of Laparoscopic \\ Surgery, 72 Powstancow Wlkp. Street, 70-111 Szczecin, Poland \\ Received: 2 August 2001/Accepted in final form: 6 September 2001/ \\ Online publication: 8 February 2002 \\ DOI: $10.1007 / \mathrm{s} 00464-001-4229-3$
}

\section{Abstract}

Complications after endoscopic retrograde cholangiopancreatography (ERCP) usually are treated endoscopically or by traditional surgical procedure. We present two cases of laparoscopic treatment. Patient 1 had mechanical jaundice. Ultrasound scan showed a common bile duct (CBD) extended to $11 \mathrm{~mm}$, and ERCP disclosed a stone wedged up in the extrapancreatic part of the CBD. Endoscopic techniques did not help to remove the stone, and finally tore off the Dormia basket, leaving it in the bile ducts. After unsuccessful attempts at its endoscopic evacuation, laparoscopy was performed. A choledochoscope was introduced into the CBD, and the Dormia basket was removed. However, the removal of the stone "ingrown" in the wall of the CBD was not successful, leading to a laparotomy. Patient 2 had cholecysto- and choledocholithiasis. On ERCP, multiple stones filling the CBD were found. Combining ECRP with extracorporeal shock-wave lithotripsy, sphincterotomy, and mechanical lithotripsy did not lead to removal of all the stones, so an endoscopic biliary prosthesis was introduced. During consecutive ERCP, one of the prosthetic ends moved into the head of pancreas. Endoscopic attempts to remove it were unsuccessful, so laparoscopy was performed. During the operation, the CBD was incised, allowing all the remaining stones and the prosthetic device to be removed successfully. It seems that laparoscopic treatment currently may be an alternative to traditional surgery in the treatment of some complications after ERCP.

Key words: Laparoscopy - Complications post-ERCP Correspondence to: T. Hamera

\section{"Needlescopic" sigmoid resection}

P. M. Chiasson, D. E. Pace, R. A. Mustard, J. Mamazza, E. C. Poulin, C. M. Schlachta

The Centre for Minimally Invasive Surgery, St. Michael's Hospital, University of Toronto, Toronto, Ontario M5C 1R6, Canada

Received: 31 August 2001/Accepted in final form: 15 November 2001/ Online publication: 8 February 2002

DOI: $10.1007 / \mathrm{s} 00464-001-4139-4$

\section{Abstract}

Minimally invasive surgical techniques and procedures continue to evolve with the trend toward fewer and smaller instruments. To our knowledge, this is the first reported case of sigmoid colon resection utilizing needlescopic technology. The patient was a 53-year-old woman diagnosed with a malignant lesion in the midsigmoid colon at $30 \mathrm{~cm}$. A subsequent needlescopic sigmoid colon resection was performed and the patient was discharged home after an uneventful postoperative course. This case demonstrates that colon procedures that require major reconstruction may be performed needlescopically in selected patients.

Key words: Needlescopic surgery - Sigmoid resection - Laparoscopy Colorectal surgery Correspondence to: C. M. Schlachta 